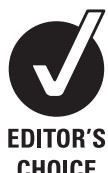

CHOICE

- Additional materials are published online only. To view these files please visit the journal online (http://bjo.bmj. com/content/96/7.toc).

${ }^{1}$ Department of Ophthalmology, University of Leicester, RKSCB, Leicester Royal Infirmary,

Leicester, UK

${ }^{2}$ NIHR Research Design Service (East Midlands), Department of Health Sciences, University of Leicester, Leicester, UK

\section{Correspondence to}

Rebecca McLean,

Ophthalmology Group,

University of Leicester, RKCSB, Leicester Royal Infirmary, Leicester, LE2 7LX, UK; rjm19@le.ac.uk

Accepted 25 March 2012

Published Online First

19 April 2012

\title{
Living with nystagmus: a qualitative study
}

\author{
Rebecca Jane McLean, ${ }^{1}$ Kate C Windridge, ${ }^{2}$ Irene Gottlob ${ }^{1}$
}

\section{ABSTRACT \\ Background/aims To identify aspects of daily living affected by nystagmus.}

Methods Semistructured interviews were conducted at the University of Leicester, UK with participants with acquired and infantile nystagmus. In total 21, participants were purposively sampled and recruited. Transcript analysis was conducted using constant comparative technique, based upon the grounded theory, to identify specific areas of living affected by nystagmus.

Results Analysis identified six domains that were adversely affected by nystagmus; visual function, restriction of movement, standing out/not fitting in, feelings about the inner self, negativity about the future and relationships. Cosmetic appearance of nystagmus, including others' avoidant response to this, was described ( $n=18)$, as was others' failure to recognise what it is like to have nystagmus $(n=18)$. Driving issues were frequently raised $(n=19)$ and restrictions in occupation choice/opportunities $(n=17)$ were highlighted. Reliance on others $(n=16)$ also emerged. Additional to other categories was an overarching and universal distress arising from nystagmus affecting every aspect of everyday life.

Conclusion Interviews revealed universally negative experiences of living with nystagmus that are previously unreported. Findings are similar to studies conducted for strabismus, in particular with respect to cosmetic impact. This study provides the content that is required to develop a nystagmus-specific quality of life tool.

\section{INTRODUCTION}

Nystagmus is an involuntary to and fro movement of the eyes which can be infantile or acquired in later life due to vestibular or neurological disease ${ }^{1}$ and leads to decreased visual acuity. ${ }^{2}$ Infantile nystagmus syndrome (INS) can be unassociated to any other visual deficits or can be associated with eye disease, such as retinal disease, albinism, low vision or visual deprivation in early life. Acquired nystagmus can lead to oscillopsia. ${ }^{1}$ Many individuals with nystagmus will adopt an abnormal head posture to position their eyes where the nystagmus is least. ${ }^{3}$ Recent research estimates the prevalence of nystagmus to be $24 / 10000^{4}$ and the impact of nystagmus is significant, with visual functioning scores in nystagmus worse than other visual disease such as age-related macular degeneration. ${ }^{5}$

Impaired vision has a wide variety of consequences for quality of life (OOL) as various eye conditions affect vision in different ways. A combination of visual, functional, psychological, social and economic factors jointly determines an individual experience. ${ }^{6}$ Vision-specific functioning measures, such as the National Eye Institute Visual Function Questionnaire (NEI-VFQ), ${ }^{7}$ are reported to be more sensitive in determining decreased functional status secondary to vision loss than general health related QOL measures such as the SF-36. Furthermore, vision 'disease-specific' QOL tools (eg, in strabismus) have shown to detect the impact that an eye condition has on the individual to a greater degree than do the more generic vision tools. $^{8} 9$ Strabismus occurs in childhood, as do some nystagmus forms. It can affect vision, but more often, it is the cosmetic effects, rather than visual, of strabismus that have more detrimental consequences. ${ }^{10}$

Further disease specific tools have been developed for use in visual conditions such as cataract, agerelated macular degeneration, retinal disease and ocular melanoma. ${ }^{11}$

However, there is as yet no nystagmus-specific QOL tool. US and European regulatory authorities strongly advocate a move to developing healthrelated $\mathrm{QOL}$ instruments that are based on patients', rather than clinicians' perspectives. ${ }^{12}$ To address the gap in understanding the domains of daily living affected by nystagmus from the perspective of those with the condition, we undertook a qualitative study in which we interviewed adult nystagmus patients. The aim was to identify the aspects of living with nystagmus that patients perceived as problematic (or the opposite) in order to understand how nystagmus affects QOL and, at a later stage, develop a nystagmus specific, patient derived, QOL instrument.

\section{MATERIALS AND METHODS Participants}

Participants were recruited from the principal investigators' neuro-ophthalmology clinic. Patients, over the age of 16 years, with acquired or infantile nystagmus were eligible for the study. As the aim of the study was to identify a wide range of issues that can impact QOL, a non-statistical, maximum variation, purposive sampling strategy was adopted to reduce the chances of omitting to collect information that has important implications. ${ }^{13}$ This sampling strategy aims to identify as diverse a range of views/experiences as possible so that participant selection is based on the likelihood of discovering divergent experiences, rather than on principles (such as sample size calculations), underpinning the use of inferential statistics. A sampling frame was therefore drawn up to guide recruitment (details of patient attributes covered by the frame are listed in table 1) which ensured as much variety as possible on a range of characteristics that included age, gender, ethnicity, varying deprivation scores based on postal code, nystagmus type, a range of visual acuities, drivers and nondrivers, parents and non-parents and living arrangements. This research adhered to the tenets of the Declaration of Helsinki. Ethical approval was 
received from the Leicestershire, Northamptonshire and Rutland Ethics Committees prior to beginning the study and informed consent was obtained from all participants.

\section{Interviews}

Semistructured, individual, face-to-face interviews were conducted using a topic guide and were audio taped. The openended questions were developed by the authors who have a range of clinical knowledge and qualitative expertise. Questions were devised to determine the impact, both good and bad, that nystagmus has on daily living. A sample topic guide can be viewed in the online supplementary file. Question responses were followed by prompts from the interviewer so that issues that were important to the interviewee could be followed up, even if they were unanticipated. As RJM was familiar to some of the participants, a choice of an unknown interviewer was also offered (KCW). All the interviews were conducted by RJM. Interviews lasted up to an hour depending upon the individual participant. Further patients were interviewed until 'theoretical saturation' was reached; where concurrent analysis revealed that additional interviews were giving rise to no issues that had not already been described by previous participants, meaning that the search for further new issues was likely to be futile. This is

Table 1 Participant demographic data. The lower the deprivation score, the more deprived the area (based on Neighbourhood Statistics from the Office for National Statistics)

\begin{tabular}{|c|c|}
\hline \multicolumn{2}{|l|}{ Gender } \\
\hline Male & 12 \\
\hline Female & 9 \\
\hline \multicolumn{2}{|l|}{ Ethnicity } \\
\hline White & 18 \\
\hline Other & \\
\hline \multicolumn{2}{|l|}{ Age } \\
\hline$<39$ years & 11 \\
\hline $40-59$ years & 8 \\
\hline$>60$ years & \\
\hline \multicolumn{2}{|l|}{ Deprivation score } \\
\hline$<10000$ & 4 \\
\hline $10001-20000$ & 5 \\
\hline $20001-32482$ & 10 \\
\hline Unable to score & 2 \\
\hline \multicolumn{2}{|l|}{ Level of education } \\
\hline University & 10 \\
\hline School & 11 \\
\hline \multicolumn{2}{|l|}{ Type of nystagmus } \\
\hline Acquired & 2 \\
\hline Infantile idiopathic & 9 \\
\hline Other infantile & 10 \\
\hline \multicolumn{2}{|l|}{ Visual acuity } \\
\hline Better than $6 / 12$ & 10 \\
\hline From $6 / 12$ to $6 / 36$ & 7 \\
\hline Worse than $6 / 36$ & 4 \\
\hline \multicolumn{2}{|c|}{ Family history of nystagmus } \\
\hline Yes & 7 \\
\hline No & 14 \\
\hline \multicolumn{2}{|l|}{ Living arrangements } \\
\hline Alone & 5 \\
\hline With others & 16 \\
\hline \multicolumn{2}{|l|}{ Driving status } \\
\hline Driver & 4 \\
\hline Non-driver & 16 \\
\hline Stopped driving & 1 \\
\hline
\end{tabular}

a team decision based on auditable evidence and is the usual means of determining sample size in qualitative research. ${ }^{14}$

\section{Data analysis}

Audio recordings were transcribed verbatim and data analysis was conducted using a constant comparative approach based on the grounded theory. ${ }^{13} 14$ Analysis proceeded in four steps. First, the initial four transcripts were 'open coded' by two researchers (RJM and KCW). This involved intensive 'line-by-line' reflection and summarising of transcript content, to give lists of open codes (phrases or words), each of which described a unit of meaning within the transcript. Second, the lists of several hundred codes were discussed by the researchers and then provisionally grouped into organising themes/categories, which provided the initial coding frame. Third, one researcher (RJM) used NVivo ${ }^{15}$ to systematically assign text from all the transcripts to the coding frame, actively searching for any evidence that contradicted the emerging coding frame while doing so (constant comparison). Fourth, the coding frame was continually discussed and revised as necessary when new or contradictory themes/categories appeared, enabling the coding frame to develop in a way that accurately reflected issues emerging in participants' accounts. For instance within the theme that included negative feelings about the 'inner self' were several subthemes such as low self-esteem and sadness or depression, but in transcript 9 a new subtheme emerged ('guilt') that required a revision of the coding frame. A second researcher (KCW) checked the assignment of text to categories as a method of improving rigour. A clear audit trail was generated within the software; the process by which the coding frame was derived from participant accounts is available for inspection by other researchers.

\section{RESULTS}

\section{Participants' characteristics}

Theoretical saturation was reached by 21 participants, at which recruitment ceased. Two participants had acquired nystagmus following multiple sclerosis, nine had INS unassociated with afferent deficits and ten participants had INS associated with other eye diseases which included albinism, achiasmia, achromatopsia and congenital cataracts. Table 1 summarises the characteristics of the sample (more detailed participant characteristics, including nystagmus waveforms, can be found in the online supplementary file to enable cross-referencing).

\section{Domains of living affected by nystagmus}

Analysis revealed six domains of living that were adversely affected by nystagmus: visual function, restriction of movement (both physical and social), standing out/not fitting in, feelings about the inner self, negativity with regards to the future and relationships. Thirty-four subcategories, some of which were not mutually exclusive, made up the six themes (box 1). The most important themes are reported as determined by the frequency in which they appeared in the transcripts. Each area is illustrated by transcript extracts that gave rise to that particular category. An additional table is available in the online supplementary data that illustrates the domains that each individual participant referred to during the interview and the number of times referred. Although many themes were recounted by the participants, an overarching theme that every participant discussed emerged $(n=21)$, that nystagmus affects every aspect of everyday life (box 2). Distress was very apparent during the interviews and 10 participants wept when describing the impact of nystagmus. 
Box 1 Domains and subcategories that emerged from the transcripts with the total number of interviewees reporting the topic

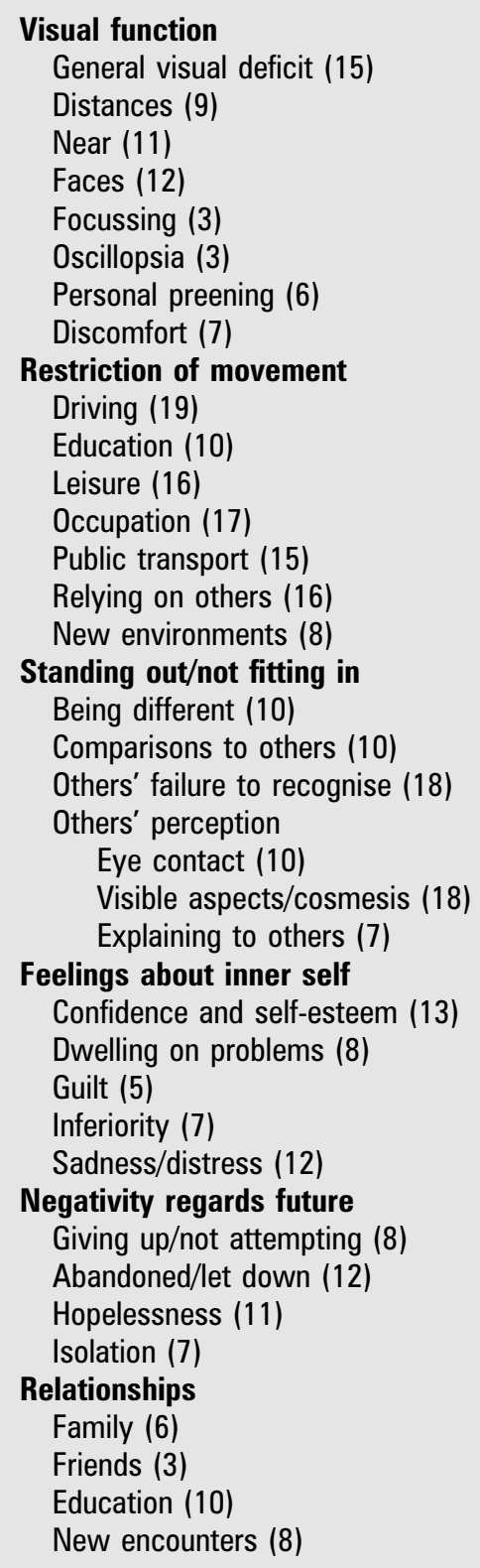

\section{Visual function}

Participants discussed generalised visual deficits due to nystagmus $(n=15)$ and also the more specific areas of distance $(n=9)$ and near vision $(n=11)$. Tasks that are specifically affected by nystagmus such as watching the television, reading street signs and reading text were apparent in the transcripts. Further visual difficulties also arose with facial recognition $(\mathrm{n}=12)$ (table 2$)$.

\section{Restriction of movement}

Participants felt constrained both physically (getting from place to place) and socially because of their nystagmus. Nineteen of the interviewees discussed being unable to drive and the restrictions this imposes on travel and also on other areas of daily living such as occupation. Occupation, in the context of driving and with regard to life choices and opportunities, arose

\section{Box 2 Quotes that illustrate the overlying theme 'affects} every aspect of everyday life'

Overlying theme-affects everything

"It creeps into everything really, everyday life." (Patient 7)

“...it's all rolled up into one really it's just there all the while sort of thing. " (Patient 4)

"...it affects your daily life and it will do for the rest of your life." (Patient 16)

“...every aspect of growing up and becoming an adult has been affected by it." (Patient 13)

"I just want to get on with stuff normally and it not bother me and it not get in the way of doing what I do every day." (Patient 1).

frequently in the interviews ( $\mathrm{n}=17)$. Public transport was an area mentioned by many of our participants $(n=15)$. Leisure activities $(n=16)$ and reliance on other people for help with tasks was also highly reported $(\mathrm{n}=16)$ (table 2$)$.

\section{Standing out/not fitting in}

The cosmetic appearance of the nystagmus, and awareness that others' responses were avoidant or negative to this, were significant to the participants $(n=18)$. Issues also arose with regards to head posture. Ten participants reported that nystagmus impacted upon making eye contact. Thoughts about being different $(n=10)$ and direct comparisons to others who do not have nystagmus $(n=10)$ suggested that the interviewees perceived themselves to be less able because of the nystagmus. The predominant issue within this theme was the failure by others to recognise what it is like to have nystagmus and the lack of understanding that exists about the condition $(n=18)$ (table 3).

\section{Feelings about inner self and negative future}

Nystagmus was reported as affecting an individual's confidence and self-esteem $(n=13)$. Sadness and distress because of nystagmus was also expressed $(n=12)$. Feelings of abandonment, particularly by the medical community, were recounted by more than half of those interviewed $(n=12)$. Feelings of hopelessness and being told by others that there was no hope emerged $(\mathrm{n}=11)$. Many participants described giving up and not attempting activities for fear of failure $(n=8)$ (table 3$)$.

\section{DISCUSSION}

The areas mentioned most frequently were visual function, driving, others noticing the visible aspects and the failure of others to recognise what it is like to have nystagmus. Restriction of movement, which included both physical and social movement was discussed by the majority of our interviewees. Issues with confidence, self-esteem, hopelessness and sadness also featured.

Although some of the affected areas of daily living that surfaced in our interviews are typically found in vision-specific QOL tools such as the NEI-VFQ and IVI (Impact of Visual Impairment Questionnaire ${ }^{16}{ }^{17}$ we did also elicit themes that do not currently appear, further emphasising the need to develop a tool that is specific to nystagmus. A consequence of nystagmus is reduced visual acuity; therefore, it was expected that visual function would materialise during the interviews. This reduction in visual acuity means that the majority of individuals with 
Table 2 Quotes that illustrate the domains visual function and restriction of movement

\section{Visual function \\ General visual function}

Face recognition

Restriction of movement Driving

Public transport

Occupation

Leisure activities

Relying on others
"Er vision, I'd say it's poor cos I know it could be better and like I said before you can't get away from your vision so it's there all the time." (Patient 7)

"Just trying to I suppose if you know if I wanted to read for a long time I mean I've never sat down and really read books. But that is probably why I don't because you just get tired just reading, concentrating to read for so long." (Patient 15)

"My Vision...obviously my distance vision is not great, what I would normally be able to read is not great. Also reading small print on sort of telephone directories and things...if there's poor light quality or if I'm tired then I am then having to resort to using a magnifying glass." (Patient 21)

"I remember when I was a kid I got lost quite easily because I couldn't find, if I wandered off and then my mum would disappear and I couldn't find her cos I can't pick faces out in a crowds so yeah that was sometimes a problem definitely." (Patient 1)

“...my recognising people; there's many time I walk past people and then they obviously comment you didn't acknowledge them. Other times I can acknowledge somebody and it's not the person I thought it was when then that can be embarrassing." (Patient 10)

"I've always found that I feel a bit anti-social not being able to recognise people when you're going out and that." (Patient 16)

"For me it's not being able to drive that's the main that's the main issue. But I don't if I could just get my eyesight just so I could drive and I would be happy I feel I suppose." (Patient 7)

"Other things that worry me about becoming a parent-not being able to drive. I'd have to structure my life quite differently, choose where I live but essentially just things I need to be close to, rely on public transport which I really hate. And rely on other people a bit too much as well." (Patient 13)

"Erm it has restricted in what I can do for a erm for a living. Because I can't get a driving licence so therefore it restricts erm it has restricted me quite a lot in the past and it's still doing so. In the fact that I can't become any higher in the job I am at the moment erm because I can't drive." (Patient 14)

"You have to think whenever you're going anywhere because you have to make sure you can read the bus numbers. The same with train time boards, you have to think about it, no matter what you do, wherever you go, you have to think about it." (Patient 1)

"...it didn't restrict the type of job but it restricted where I worked because I was limited to public transport." (Patient 5)

"...I wanted to join the Navy, I wanted to join the police... the jobs that I wanted to do required that you had a certain level of vision. Job wise it has held me back." (Patient 15)

"Erm into working life because no driving license severely restricted the sort of work I could do. You know had I not had this thing wrong with me we may have lived somewhere else and I may have done a different job." (Patient 12)

"You just can't see what's going on. Anything like that with a ball or a fast moving object forget it, you are not going to be able to see it. Any sporting event really and going to the theatre, everything really, you just can't see what's going on." (Patient 6)

"Pretty much anything to do with eye co-ordination, football, tennis or anything like that. You're just not as god as anybody else and it's obvious." (Patient 19)

"Leisure tended to be things that I could do on my own where it didn't involve other people having to tolerate my ball game skills." (Patient 12)

"Big problem, big problem not only because you can't get anywhere because public transport by and large is rubbish and it's hugely expensive, but also feelings of self-worth and not being able to drive I just and being reliant on my wife to ferry me anywhere it just feels hideous." (Patient 2)

"Erm every day I mean cos I can't read of projectors and stuff like that. I know it feels makes you feel kind of dependent on someone taking notes for me and stuff...kinda helpless in a way and dependent on others and I don't like that." (Patient 18)

"Lack of independence and I don't just mean getting around I mean being dependant on other people. I find this very frustrating because when l've studied up to degree level I'm not a stupid person but yet you're made to feel a bit stupid because you can't do simple things." (Patient 21) nystagmus have issues around driving and this was also emphasised within the transcripts.

A key area that was reported by the participants in our study was the feeling of standing out and/or not fitting in. The cosmetic appearance of the nystagmus was of the utmost importance because of awareness that others' responses to this were avoidant or otherwise negative. Cosmetic effects were described as affecting the way participants interacted with others including avoidance of eye contact. The cosmetic effect of nystagmus is an area not previously examined although similar findings have been reported in strabismus where a psychosocial impact has been established, affecting self-image and interpersonal relationships and self-esteem ${ }^{18}$; aspects that were found to be important for nystagmus. It is possible that when considering treatment for nystagmus, the cosmetic effects are underestimated. Our results imply that assessing efficacy of treatments for nystagmus should not be based just upon visual function but also upon cosmetic considerations. Recording eye movement can aid in assessing cosmetic changes and should be considered an important outcome measure to use in clinical trials alongside measures of visual function.

Others' failure to recognise what it is like to have nystagmus and people's misunderstanding/lack of knowledge about the condition is upsetting. Ultimately, this has implications for relationship-building, personal and professional, a topic that is also affected by strabismus. Visible strabismus is reported to negatively influence the ability to obtain employment ${ }^{19}$ and the

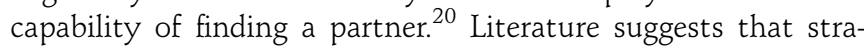
bismus is still misunderstood by the general population and has a detrimental influence on major life goals. If this is the case for strabismus where the prevalence is $3 \%$ to $5 \%$ of the population ${ }^{21} 22$ we postulate that the awareness of nystagmus as a condition, which has a far lower prevalence of $0.24 \%$, ${ }^{5}$ is minimal and has social and psychological consequences for those with nystagmus. The statement that nystagmus 'affects everything' frequently surfaced during the interviews. This coupled with the fact that almost half of the participants $\left(n=10^{\mathrm{i}}\right)$ wept while being interviewed confirms the importance of accurately assessing QOL in this group of patients.

The aim of this study, to identify areas of daily living that are affected by nystagmus from the perspective of individuals who have the condition, is considered to be best addressed by qualitative methods. ${ }^{12}$ However, this approach may have some limitations. Therefore, every effort was made to ensure that

i*Participants $1,4,6,8,10,11,13,14,15$ \& 21 wept while being interviewed. These participants had a range of visual functioning and nystagmus characteristics as documented in the online supplementary file of participant characteristics. 
Table 3 Quotes that illustrate the domains standing out/not fitting in, feelings about inner self and negative future

Standing out/not fitting in
Visible aspects/cosmesis

Eye contact

Comparisons to others

Others failure to recognise

Feelings about inner self Confidence and self-esteem

Sadness/distress

Negative future

Abandoned/let down

Hopelessness

Giving up/not attempting

"..the wobble, if that were removed or reduced it would make a massive difference. I'm often in situations where nobody need know or would know that I am visual impaired at all were it not for my nystagmus. But because it's there it makes a massive difference. To me emotionally, psychologically it makes a massive difference." (Patient 6)

"Probably the fact that my eyes are wobbling cos I don't know any different to what I should be seeing because that's how was born. So if you know your eyes and head are wobbling and people are looking at you thinking why the bloody hell's your head wobbling then it's harder to accept." (Patient 3).

"...you would have to sit with your head sort of like on a slant you know to try and get your vision and then people look at you so you feel a bit conscious there. So you'd find yourself straightening your head up and probably not being able to see erm very well but you'd just put up with it because you didn't want people to think you were weird or anything." (Patient 5)

“...What's that with your eyes why are they moving .....I don't tend to look at people in the eye or if I do it's sort of fleeting. Cos I still feel embarrassed about them seeing my eyes moving and thinking what what's she doing." (Patient 11)

“...when it's pointed out to you time after time after time after time it does get to you...I actually avoid looking at people straight in the eye." (Patient 14)

"Just feeling different all the time. Just struggling to do things that everyone else can do straight the way. You always you always just feel that you're not as good as other people." (Patient 3)

“... going to University it became more of a tiredness thing that was an issue rather than as a vision problem. Erm just not being able to fit in as much in a day as everyone else and then at work that is the main problem tiredness and how I have to work a shorter day and can't fit in as much in the evenings and stuff." (Patient 13)

"And it's frustrating because just every now and again there's a little boy in me just pleads I want someone to understand me and I'd like to somebody actually understand how bad I'm feeling about it and because people can't, they can't appreciate." (Patient 2)

“...it's more people's misunderstanding of the problem that is upsetting. It's not direct problems I face, it's trying to make other people understand those problems." (Patient 13)

"I'd be a lot more confident, more outgoing and have a different career...I think things would change significantly if I didn't have this condition". (Patient 20)

"I feel that if I didn't have it I'd probably have a greater more confidence and I'd be able to live in a better way" (Patient 8)

"Again feeling of self-worth is involved here...huge problem with self-esteem, huge problem with not being able to bring in much money and a huge problem just trying to get through." (Patient 2)

"Depressed sometimes. Very depressed. You keep saying to yourself, oh make an effort, but you don't, you just don't." (Patient 4) "I used to feel ugly because people were so cruel at school cos children are and that sort of sticks with you throughout your life. Sometimes I feel a bit worthless, as though you're a nobody cos I'm a bit freaky and different." (Patient 5)

"There was a time where it actually occurred to me that I should feel suicidal about it because it felt like it was difficult just to go through the day and put up with this." (Patient 2)

"Go away and forget about it yourself and that's basically what l've been told all my life by the professionals...it's always been a case of well what do you expect us to do? It's nystagmus there's nothing we can do about it. So perhaps they could be a little a bit more sympathetic and at least pretend to be doing something." (Patient 16)

"I went for forty years and nobody touched me, nobody discussed it and yet it's on my medical records and yet nobody was out there for me. So there was no help." (Patient 9)

"I was told that there was nothing available at all. There was never gonna be any treatment." (Patient 3)

"I had an optician who when I was about 10 said to me...well young fellow someone has got to tell you and it might as well be me...you'll never have a driving license." (Patient 12)

"I think the medical profession in general because it's been over 40 years and I was never told anything, I had no hope." (Patient 9) "Or playing sports you know your not going to hit it so why attempt playing cricket cos you could be stood there all day trying to hit the ball and you know your not gonna hit it cos your not gonna see it." (Patient 7)

"Erm, cos I don't want to show myself up. Cos the first thing I'll say is I can't read it or I'll try and read it and get it wrong. And then they mock you because you've got it wrong. And then I then feel belittled that I couldn't see it and yet at the end of the day it's not my fault you know but." (Patient 9)

participants were not asked leading questions. Transcripts were examined thoroughly by more than one member of the research team and regular meetings were held with experienced qualitative researchers to discuss developing themes. As this is the first study for nystagmus, there is no existing research to compare our findings with. However, our findings are similar to those reported for QOL strabismus studies (which like nystagmus affects vision/cosmesis and can occur in childhood) allowing us to make comparisons.

A number of studies are available that report treatment options for nystagmus. ${ }^{23}$ One randomised controlled trial reports that gabapentin and memantine significantly reduce INS and improve vision as compared with placebo. ${ }^{24}$ However, visual and social functioning questionnaires that were administered showed no significant differences between active treatment groups and placebo. A possibility is that the vision specific QOL instruments used are not sensitive to the domains of living that are affected by nystagmus. Our study has uncovered a number of themes that are affected by nystagmus, for example, cosmesis, social restrictions and psychological distress, that to date have not been considered when describing the impact of nystagmus and evaluating treatments. Although poor visual acuity would directly contribute to the impacted domains of living raised by our interviewees such as visual function and restriction of movement, our interviews clearly show the need to consider much more than poor visual acuity when investigating nystagmus. The six domains that emerged provide the necessary evidence to develop a patient-derived, disease-specific, $\mathrm{QOL}$ tool for nystagmus, allowing questionnaire items to be written that are grounded in the perspectives of individuals with nystagmus.

Acknowledgements The authors would like to acknowledge Elizabeth Ockleford and Frank Proudlock for their contribution.

Contributors All authors contributed substantially to this article.

Funding This study was supported by Fight for Sight and Nystagmus Network UK. Competing interests None. 
Patient consent Obtained.

Ethics approval Ethics approval was provided by Leicestershire, Northamptonshire and Rutland Ethics Committees.

Provenance and peer review Not commissioned; externally peer reviewed.

\section{REFERENCES}

1. Leigh RJ, Zee DS. The Neurology of Eye Movements. 4th edn. Oxford: Oxford University Press, 2006.

2. Chung ST, Bedell HE. Velocity criteria for "foveation periods" determined from image motions simulating congenital nystagmus. Optom Vis Sci 1996;73:92-103.

3. Abadi RV, Whittle J. The nature of head postures in congenital nystagmus. Arch Ophthalmol 1991;109:216-20.

4. Sarvananthan N, Surendran M, Roberts EO, et al. The prevalence of nystagmus: the Leicestershire nystagmus survey. Invest Ophthalmol Vis Sci 2009;50:5201-6.

5. Pilling RF, Thompson JR, Gottlob I. Social and visual function in nystagmus. $\mathrm{Br} J$ Ophthalmol 2005;89:1278-81.

6. CERA. Focus on Low Vision. 2007. http://www.cera.org.au/publications/reports/ Focus\%20on\%20LowVision.pdf (accessed 14 Aug 2009).

7. Parrish RK, Gedde SJ, Scott IU, et al. Visual function and quality of life among patients with glaucoma. Arch Ophthalmol 1997:115:1447-55.

8. van de Graaf ES, van der Sterre GW, Polling JR, et al. Amblyopia \& Strabismus Questionnaire: design and initial validation. Strabismus 2004;12:181-93.

9. Hatt SR, Leske DA, Holmes JM. Responsiveness of health-related quality-of-life questionnaires in adults undergoing Strabismus surgery. Ophthalmology 2010:117:2322-8

10. Hatt SR, Leske DA, Kirgis PA, et al. The effects of strabismus on quality of life in adults. Am J Ophthalmol 2007;144:643-7.
11. de Boer MR, Moll AC, de Vet $\mathrm{HC}$, et al. Psychometric properties of vision-related quality of life questionnaires: a systematic review. Ophthalmic Physiol Opt 2004;24:257-73.

12. Ring L, Gross CR, McColl E. Putting the text back into context: toward increased use of mixed methods for quality of life research. Qual Life Res 2010;19:613-15.

13. Flick U, Flick U, Kvale SD, et al. The Sage Qualitative Research Kit. London: SAGE 2007.

14. Charmaz K. Constructing Grounded Theory. London, Thousand Oaks, Calif: Sage Publications, 2006.

15. NVivo Qualitative Data Analysis Software. 8th edn. OSR International Pty Ltd, 2008

16. Mangione CM, Lee PP, Gutierrez PR, et al. Development of the 25-item National eye Institute visual function questionnaire. Arch Ophthalmol 2001;119:1050-8.

17. Hassell JB, Weih LM, Keeffe JE. A measure of handicap for low vision rehabilitation: the impact of vision impairment profile. Clin Exp Ophthalmol 2000;28:156-61.

18. Archer SM, Musch DC, Wren PA, et al. Social and emotional impact of strabismus surgery on quality of life in children. J AAPOS 2005;9:148-51.

19. Coats DK, Paysse EA, Towler AJ, et al. Impact of large angle horizontal strabismus on ability to obtain employment. Ophthalmology 2000;107:402-5.

20. Mojon-Azzi SM, Potnik W, Mojon DS, et al. Opinions of dating agents about strabismic subjects' ability to find a partner. Br J Ophthalmol 2008:92:765-9.

21. Donnelly UM, Stewart NM, Hollinger M. Prevalence and outcomes of childhood visual disorders. Ophthalmic Epidemiol 2005;12:243-50.

22. Williams C, Northstone K, Howard M, et al. Prevalence and risk factors for common vision problems in children: data from the ALSPAC study. Br J Ophthalmol 2008;92:959-64.

23. McLean RJ, Gottlob I. The pharmacological treatment of nystagmus: a review. Expert Opin Pharmacother 2009;10:1805-16.

24. McLean R, Proudlock F, Thomas S, et al. Congenital nystagmus: randomized, controlled, double-masked trial of memantine/gabapentin. Ann Neurol 2007:61:130-8. 